\title{
Are Family Doctors Compliant with Breast Family History Guidelines?
}

\author{
Joe Thomas $^{1 *}$, Michael Sugrue ${ }^{2}$, Sharon Curran ${ }^{2}$, Michelle Furey $^{1}$, Ryan Sugrue $^{1}$ \\ ${ }^{1}$ National University of Ireland Galway, University Road, Galway, Ireland \\ ${ }^{2}$ Donegal Clinical and Research Academy, Breast Centre North West Letterkenny Hospital, Donegal, Ireland \\ Email: *thomas1@nuigalway.ie
}

Received August 7, 2013; revised August 28, 2013; accepted September 4, 2013

Copyright (C) 2013 Joe Thomas et al. This is an open access article distributed under the Creative Commons Attribution License, which permits unrestricted use, distribution, and reproduction in any medium, provided the original work is properly cited.

\begin{abstract}
Introduction: Optimizing breast cancer care involves accurate risk assessment. Referrals to secondary care need to be appropriate both in terms of healthcare resource utilisation and the reduction of unnecessary patient anxiety. Aim: This study undertook an evaluation of family doctors compliance with NICE guidelines for asymptomatic family history referrals to a breast unit. Methods: A retrospective audit of general practice in County Donegal was carried out between January 2010 and May 2011. NICE guidelines and IBIS computerised model were used to assess whether referrals were appropriate. Results: $77.6 \%$ (90/116) met a criterion for secondary care referral. 51.7\% (60/116) met the NICE criteria and $64.7 \%(75 / 116)$ met the IBIS criteria for referral to secondary care. $38.8 \%(45 / 116)$ met both. 6 were of low risk, 45 were of moderate risk and 1 was of high risk. 80.4\% (45/56) of the patients who did not meet the NICE criteria, failed to do so because they had one $1^{\text {st }}$ degree relative with breast cancer who was over the age of 40 . Conclusion: $77.6 \%$ of referrals complied with international criteria for referral to secondary care. A greater understanding of what constitutes appropriate referral of $1^{\text {st }}$ degree relatives would enhance the referral process.
\end{abstract}

Keywords: Referral Guidelines; Family History; Breast Cancer; Risk Assessment

\section{Introduction}

Increasing accuracy of triage and risk assessment is important in optimizing breast cancer care and reducing the burden on medical resources. Growing public awareness of the genetic component of cancer has led to an increase in the number of family history referrals [1]. The probability of a woman developing breast cancer by the age of 80 who has no affected first degree relatives is $7.8 \%$, one affected first degree relative is $13.3 \%$ and two affected first degree relatives are $21.1 \%$ [2]. Genetic predisposition is an important risk factor. Mutations such as BRCA1 and BRCA 2 have been found in $5 \%$ of breast cancer patients and $15 \%-20 \%$ of breast cancer patients with positive family history. The lifetime risk of female mutation carriers approaches $60 \%-80 \%$ [3]. Many other factors increase the risk of breast cancer and interact in complex and relatively uncharted pathways amplified through prolonged oestrogen exposure. International guidelines on family history risk assessment and referral to secondary and tertiary care are well established. The

\footnotetext{
"Corresponding author.
}

NICE guidelines are under constant review [4,5]. Family doctors on the front line delivery of care have been involved in the development of guidelines. The use of guidelines has been shown to improve the appropriateness of referrals [6]. In addition several computerised models have been developed to assess the risk of breast cancer based on family history. These include the Gail, Claus, Ford and IBIS (Tyrer-Cuzick) models. The IBIS software (Tyrer-Cuzick model), has been found to be the most consistently accurate model for the prediction of breast cancer when compared to Gail, Claus and Ford models [7]. The Manchester, Penn II and BOADICEA models were developed more recently. A study showed that the IBIS model had a higher specificity compared to these models; however it also had the lower sensitivity. Some may argue that a test with high sensitivity but low specificity for BRCA mutations may be more appropriate as the diagnostic tests carry few negative consequences [8]. Family doctors are regularly requested by patients for advice involving family history and breast cancer [9]. This study undertook an evaluation of family doctors in compliance with NICE guidelines for asymptomatic family history referrals to a breast unit. 


\section{Methods}

A retrospective review was undertaken of all patients presenting to the breast unit at Letterkenny Hospital in an ethically approved study between January 2010 and May 2011. Letterkenny Hospital's Breast Unit is a designated centre for the provision of breast cancer under the Irish National Cancer Control Programme. It serves a population of 160,000. Letterkenny is situated in County Donegal and has 110 family practitioners who are linked to a continuous medical education programme including breast education. 2733 patients attended the breast clinic from January 2010 to May 2011. Guidelines for referral from primary to secondary care were obtained from the NICE guidelines: Familial Breast Cancer, the classification and care of women at risk of familial breast cancer in primary, secondary and tertiary care [4]. The IBIS software (utilising the Tyrer-Cuzick model) was also used to assess patient statistical risk both in terms of a 10 year risk and a lifetime risk in compliance with the NICE guidelines. Family practitioners referred patients on the basis of their clinical assessment. There are no formal triage guidelines for family history referrals. The IBIS criteria used for this study is based on the risk stratification outlined by the NICE guidelines [4]. This is summarised in Table 1. The NICE criteria for referral to secondary care is summarised in Table 2. For assessing risk using the IBIS criteria the cohort of patients was divided into those aged 40 - 49 and those in other age groups. For patients in the age group 40 - 49 the 10 year risk and lifetime risk was calculated and then the patients were allocated into the risk groups defined by NICE guidelines. For patients not in the age group $40-49$, their lifetime risk was calculated only. All charts were obtained from medical records after ethical approval. Demographic data, general risk factors and specific family history data was collected. Each of the seven criteria of the NICE guidelines for referral to secondary care was allocated a number which can be seen in Table 2 .

\section{Results}

116 asymptomatic female patients, mean age $46.8 \pm 12.3$ years (range 19 - 79) were studied. None had breast cancer at the time of the study. $77.6 \%(90 / 116)$ met a criterion for secondary care referral. $51.7 \%(60 / 116)$ met the NICE criteria and $64.7 \%(75 / 116)$ met the IBIS criteria

Table 1. IBIS criteria risk stratification.

\begin{tabular}{|c|c|c|c|}
\hline & Low Risk & Moderate Risk & High Risk \\
\hline 10-Year Risk ${ }^{*}$ & $<3 \%$ & $3 \%-8 \%$ & $>8 \%$ \\
\hline Lifetime Risk & $<17 \%$ & $17 \%-30 \%$ & $>30 \%$ \\
\hline $\begin{array}{c}\text { Risk BRCA1/2/TP53 } \\
\text { Mutation }\end{array}$ & & & $>20 \%$ \\
\hline
\end{tabular}

${ }^{*}$ Calculated for patients aged 40 - 49 only. for referral to secondary care. $38.8 \%(45 / 116)$ met both. $22.4 \%(26 / 116)$ met neither NICE or IBIS criteria for referral. Table 3 shows the number of patients that met each NICE criterion. The majority of patients, $58.3 \%$, met criteria number 5 (one $1^{\text {st }}$ degree relative and one $2^{\text {nd }}$ degree relative with breast cancer). Figure 1 shows the compliance of patients with NICE criteria for family history referral stratified by age groups. It shows that the majority of patients referred are in the 40 - 49 age group and that as age increases the referrals are more likely to be inappropriate. Using the IBIS criteria, 6 patients were found to be low risk, 45 of moderate risk and 1 of high risk in the age group $40-49$ years. For those in the other age groups collectively, 35 were found to be of low risk, 27 of moderate risk and 2 of high risk. Only one patient had risk of BRCA 2 mutation greater than $20 \%$. Figure 2 shows the risk stratification of the patients, into low, moderate and high risk groups using the IBIS scoring system, in different age groups. It shows that the younger age groups ( $<49$ years) are more likely to referred appropriately than the older age groups. Of the 56 patients that did not meet the NICE criteria for family history referral; 45 did not meet the criteria as they had a first degree relative with breast cancer who was greater than age 40 at time of diagnosis and therefore did not meet criteria 1 of the NICE guidelines set by this study (Table 2). Two

Table 2. NICE criteria.

\begin{tabular}{|c|c|}
\hline & NICE Criteria for Secondary Care Referral \\
\hline 1 & $1^{\text {st }}$ degree female relative with breast cancer $\leq 40$ years \\
\hline 2 & $1^{\text {st }}$ degree male relative with breast cancer \\
\hline 3 & $\begin{array}{l}1^{\text {st }} \text { degree relative with bilateral breast cancer where first pri- } \\
\text { mary at age }<50\end{array}$ \\
\hline 4 & Two $1^{\text {st }}$ degree relatives with breast cancer \\
\hline 5 & One $1^{\text {st }}$ degree and one $2^{\text {nd }}$ degree relative with breast cancer \\
\hline 6 & $\begin{array}{l}\text { One } 1^{\text {st }} \text { or } 2^{\text {nd }} \text { degree relative with breast cancer AND one } 1^{\text {st }} \text { or } \\
2^{\text {nd }} \text { degree relative with ovarian cancer }\end{array}$ \\
\hline 7 & Three 1 st or 2 nd degree relatives with breast cancer \\
\hline
\end{tabular}

${ }^{*}$ There must be at least one $1^{\text {st }}$ degree relative with breast or ovarian cancer to meet this criterion.

Table 3. Distribution of patients meeting NICE criteria.

\begin{tabular}{cc}
\hline \multirow{2}{*}{ NICE Criteria } & Appropriate Referrals \\
\cline { 2 - 2 } $\mathbf{1}$ & $\mathbf{( n = 6 0 )}$ \\
$\mathbf{2}$ & $20(33 \%)$ \\
$\mathbf{3}$ & 0 \\
$\mathbf{4}$ & $2(3.3 \%)$ \\
$\mathbf{5}$ & $11(18.3 \%)$ \\
$\mathbf{6}$ & $35(58.3 \%)$ \\
$\mathbf{7}$ & $7(11.7 \%)$ \\
& $14(23.3 \%)$ \\
\hline
\end{tabular}




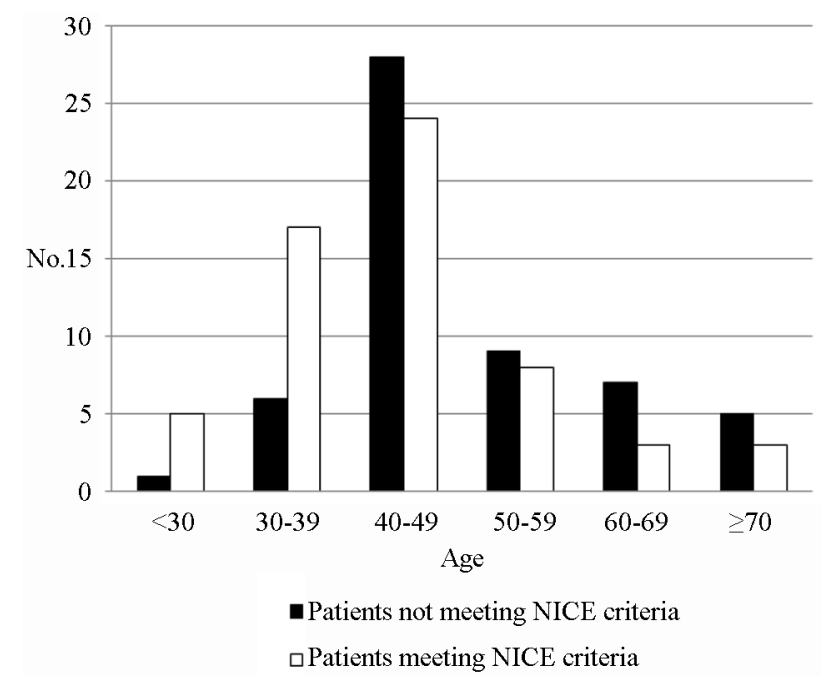

Figure 1. Compliance with NICE family history referral guidelines $\mathbf{n}=\mathbf{1 1 6}$.

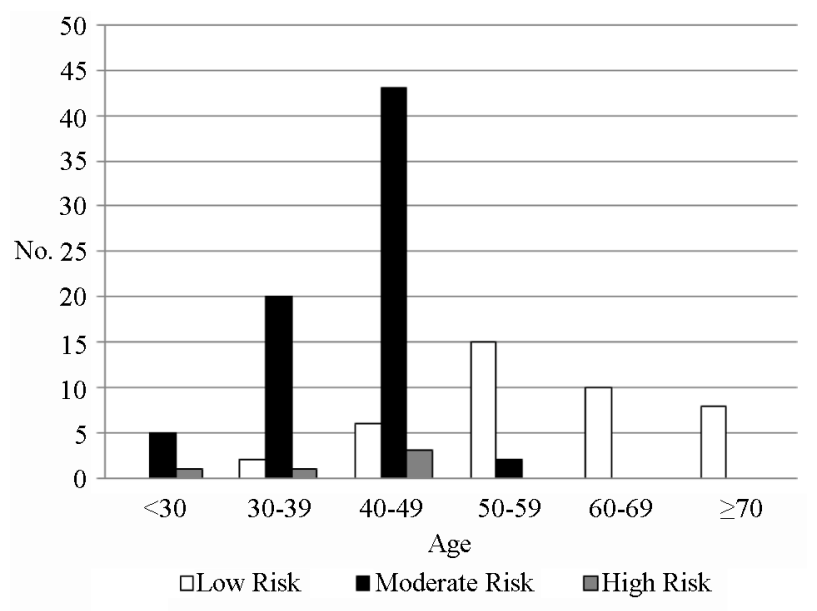

Figure 2. Classification of patients with IBIS scoring system, $\mathbf{n}=116$.

patients had one $1^{\text {st }}$ degree relative with bilateral breast cancer who was greater than age 50 and therefore did not meet criteria 3 . Two patients had one $2^{\text {nd }}$ degree relative with breast cancer and one $2^{\text {nd }}$ degree relative with ovarian cancer therefore did not meet criteria 6 . One patient had only one relative with ovarian cancer and 6 patients had less than 3 second degree relatives with breast cancer and therefore did not meet criteria 7 (Figure 3). Two of these patients also had third degree relatives with breast cancer and one had a third degree relative with ovarian cancer. Third degree relatives are not included in the NICE criteria for family history referral.

\section{Discussion}

Breast cancer services were re-organised in Ireland in 2010 with the introduction of designated cancer services. Referral guidelines and processes for referral were

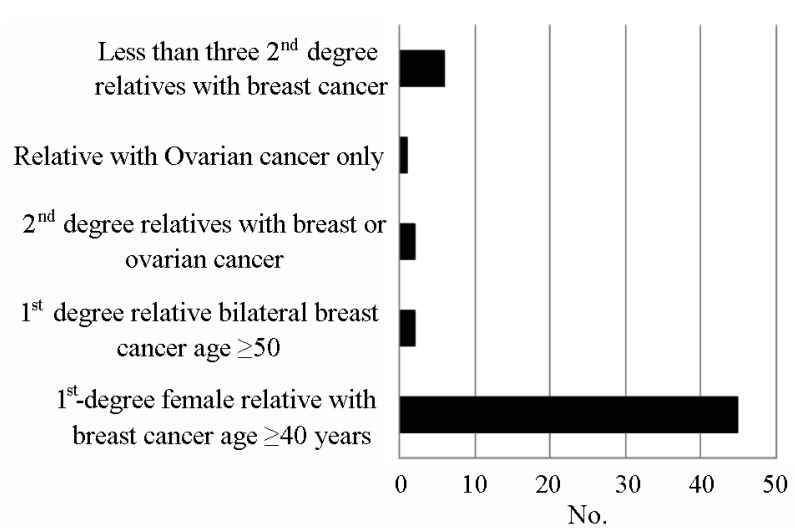

Figure 3. Reasons for non-compliance with NICE criteria.

streamlined and regulated. Patients were triaged and prioritised to urgent early or routine review. A tick box for family history was included in the paper or electronic referral process. The criteria for family history referral were not identified however. This was left to the discretion of the referring family doctor. The NICE guidelines are comprehensive well regarded triage tools. Many breast services utilise such triage and risk assessment tools in conjunction with either manual or computer aided risk assessment tools. Letterkenny Breast Unit has utilised IBIS risk assessment program since 2009 on all new referrals to the unit. Letterkenny Hospital is a regional rural hospital and extensive education program that has been undertaken over a year period with the 100 or so local referring family doctors. Patients identified as high risk (10 year risk of greater than $8 \%$ in the $40-49$ age group or lifetime risk of greater than $30 \%$ at any age or a BCRA risk greater than 20\%) were referred for Genetic Counselling and Assessment at the National Centre for Medical Genetics. A similar pilot study conducted at Letterkenny Hospital in 2010 showed that only $45 \%$ of patients referred and or seen in secondary care met appropriate family history referral criteria. Through educational programs engaging family care and the breast centre, there has been a $32.6 \%$ increase in appropriate referrals [10]. Compliance with family history guidelines for breast cancer has not been properly evaluated in Ireland and internationally.

A study conducted in the UK looking at compliance with referral guidelines for cancer (not just breast) found a wide variation in family practitioner referral rates for suspected cancer [11]. An American web-based study found $92 \%$ of patients not meeting criteria set by US Preventive Services Task Force were referred for genetics services [12]. This current study found that $51.7 \%$ (60/116 patients) referred in lieu of their family history met the criteria set by NICE and $64.7 \%$ (75/116 patients) met the IBIS criteria.

Although there has been a notable improvement in 
appropriate referrals between the two studies, there is a need for further refinement of assessment and triage. A number of options to increase the number of appropriate referrals can be undertaken. At the primary care level, for patients concerned about their family history, they could have a simple computerised calculation performed by their family practice either by their GP or practice nurse. Those then meeting risk threshold could be referred to secondary care. Those not meeting the threshold, if asymptomatic and with a normal examination could continue with primary care. The IBIS program is available to be downloaded free of charge (at www.ems-trials.org). More detailed analysis and storage of family history are available with other systems such as FAHRAS. Other options would include Breast Units assessing the risk and advising if referrals were appropriate. This would require the input of the Breast Coordinators and Breast Nurses. The National Cancer Control Program receives 37,000 new patients annually. Family history referrals account for $15 \%$ of referrals to symptomatic breast units (almost 5500 patients) [13]. If compliance with referral guidelines was improved by $20 \%$, there would be 1100 less referrals to the system. Not only would resource utilisation be enhanced but there would be a reduction in patient anxiety. Age seems to play a major part in referral decisions. Figure 1 (NICE) and Figure 2 (IBIS) show a trend that as the age group increases, a greater fraction of the patients are inappropriately referred in accordance with family history guidelines. This is possibly due to age being a strong risk factor for breast cancer and therefore family practitioners have a lower threshold for referral of elderly patients. Our results show that $80.4 \%$ $(45 / 56)$ of patients who did not meet the NICE criteria, failed to do so because they had one $1^{\text {st }}$ degree relative with breast cancer but was over the age of 40 (Figure 3). Figure 4 shows that this problem was evident throughout all age groups.

It shows that the majority of inappropriate referrals in

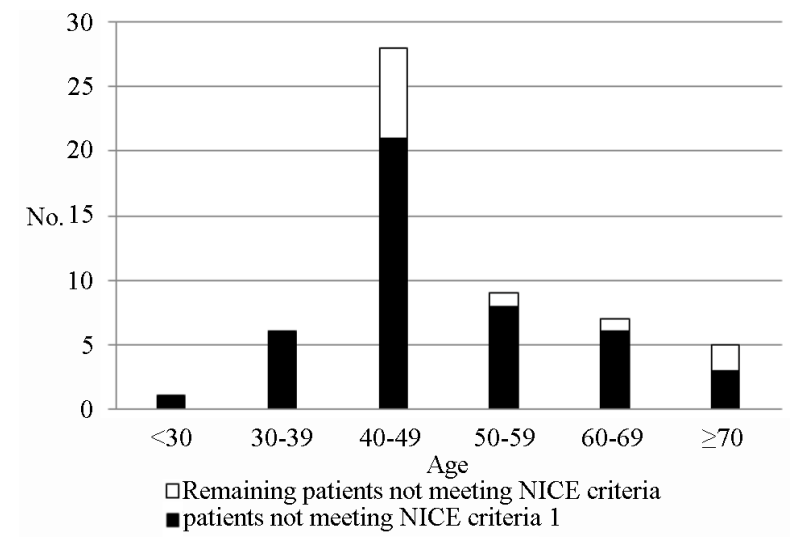

Figure 4. Proportion of patients non-compliant with NICE criteria 1. every age group were due to the failure of compliance with NICE criteria 1 ( $1^{\text {st }}$ degree relative with breast cancer aged $<40$ ). The results of this study have highlighted the major causes of non-compliance with family history guidelines. We believe there should be better education for family practitioners and patients alike that a $1^{\text {st }}$ degree relative with breast cancer alone is not a sufficient cause for referral, the relative should also be under the age of 40. Addressing this issue would significantly decrease the number of inappropriate referrals. Studies have shown that the provision of educational materials to the family practitioner can significantly improve referral decisions for patients with a family history of breast cancer and improve confidence in managing these consultations [14].

\section{REFERENCES}

[1] A. Lucassen, E. Watson, J. Harcourt, P. Rose and J. O'Grady, "Guidelines for Referral to a Regional Genetics Service: GPs Respond by Referring More Appropriate Cases," Family Practice, Vol. 18, No. 2, 2001, pp. 135140. http://dx.doi.org/10.1093/fampra/18.2.135

[2] Collaborative Group on Hormonal Factors in Breast Cancer, "Familial Breast Cancer: Collaborative Reanalysis of Individual Data from 52 Epidemiological Studies Including 58209 Women with Breast Cancer and 101986 Women without the Disease," Lancet, Vol. 358, No. 9291, 2001, pp. 1389-1399. http://dx.doi.org/10.1016/S0140-6736(01)06524-2

[3] L. K. Nathanson, R. Wooster and B. L. Weber, "Breast Cancer Genetics: What We Know and What We Need," Nature Medicine, Vol. 7, No. 6, 2001, pp. 552-556. http://dx.doi.org/10.1038/87876

[4] National Institute for Health and Clinical Excellence, "Familial Breast Cancer: The Classification and Care of Women at Risk of Familial Breast Cancer in Primary, Secondary and Tertiary Care," National Health Service (NHS), London, 2006, pp. 15-17.

[5] National Institute for Health and Clinical Excellence, "Familial Breast Cancer (Update): Guideline Consultation," National Health Service (NHS), 2010. http://guidance.nice.org.uk/CG/Wave25/1/Consultation/L atest

[6] J. M. Grimshaw and I. T. Russell, "Effect of Clinical Guidelines on Medical Practice: A Systematic Review of Rigorous Evaluations," Lancet, Vol. 342, No. 8883, 1993, pp. 1317-1322. http://dx.doi.org/10.1016/0140-6736(93)92244-N

[7] E. Amir, D. Evans, A. Shenton, F. Lalloo, A. Moran, C. Boggis, M. Wilson and A. Howell, "Evaluation of Breast Cancer Risk Assessment Packages in the Family History Evaluation and Screening Programme," Journal of Medical Genetics, Vol. 40, No. 11, 2003, pp. 807-814. http://dx.doi.org/10.1136/jmg.40.11.807

[8] S. M. Panchal, M. Ennis, S. Canon and L. J. Bordeleau, "Selecting a BRCA Risk Assessment Model for Use in a 
Familial Cancer Clinic," BMC Medical Genetics, Vol. 9, 2008, p. 116. http://dx.doi.org/10.1186/1471-2350-9-116

[9] H. Harris, I. Nippert, C. Julian-Reynier, J. Schmidtke, C. Asperen, D. Gadzicki, A. Tibben and D. G. Evans, "Familial Breast Cancer: Is It Time to Move from a Reactive to a Proactive Role?" Familial Cancer, Vol. 10, No. 3, 2011, pp. 501-503. http://dx.doi.org/10.1007/s10689-011-9434-1

[10] Z. Ahmed, G. Shields, M. Momin, S. Curran and M. Sugrue, "Breast Cancer family history risk assessment, Fact or Fantasy?" Irish Journal of Medical Sciences, Vol. 179, 2010, p. 338

[11] B. Baughan, J. Keatings and B. O'Neill, "Urgent Suspected Cancer Referrals from General Practice: Audit of Compliance with Guidelines and Referral Outcomes," British Journal of General Practice, Vol. 61, No. 592, 2011, pp. 700-706.
http://dx.doi.org/10.3399/bjgp11X606591

[12] D. B. White, V. L. Bonham, J. Jenkins, N. Stevens and C. M. McBride, "Too Many Referrals of Low-Risk Women for BRCA 1/2 Genetic Services by Family Physicians," Cancer Epidemiology, Biomarkers \& Prevention, Vol. 17, No. 11, 2008, pp. 2980-2986.

http://dx.doi.org/10.1158/1055-9965.EPI-07-2879

[13] N. O'Rourke, "Review of Referral Patterns and Triage Processes in Symptomatic Breast Units: A Hospital Perspective," National Cancer Control Programme, Health Service Executive, Dublin, 2012.

[14] E. Watson, A. Clements, P. Yudkin, P. Rose, C. Bukach, J. Mackay, A. Lucassen and J. Austoker, "Evaluation of the Impact of Two Educational Interventions on GP Management of Familial Breast/Ovarian Cancer Cases: A Cluster Randomised Controlled Trial," British Journal of General Practice, Vol. 51, No. 471, 2001, pp. 817-821. 